\title{
Utilization of Thrust Reverser Mechanism in Turbofan Engines - A Review
}

\author{
Mohd Anees Siddiqui \\ Department of Mechanical Engineering, Lucknow Institute of Technology, Lucknow, India
}

\begin{abstract}
Through this paper an attempt is made to focus on a special technology based on application of thrust reverser in turbofan engine which is common to the aviation industries but an uncommon in general. The airlines accept that thrust reverser is necessary for safe operations because it provides an added margin of safety for transport aircraft operations. In this technology, forward thrust produced by turbofan engine of aircraft is diverged to reverse direction so as to provide an additional deceleration effect during landing and power back effect. This technique is employed for improving aircraft runway performance and it is observed that by using thrust reverser especially in wet runway there is considerable reduction in landing run which is responsible for safety of passenger aircraft. Different mechanisms for thrust reverser are Cascade system, Clamshell door system and Bucket target system. Technical aspects such as engine power reverse thrust characteristics, modes of operation and speed limits of thrust reverser mechanism along with technical problems are discussed. As this mechanism is crucial for safety of aircraft therefore thrust reverser \& engine maintenance-schedule is also discussed further.
\end{abstract}

Keywords — Landing run, Turbofan engine, Thrust reverser

\section{INTRODUCTION}

Thrust reversers on turbofan aircraft provide a significant way of increasing the rate of deceleration from high speed during the initial stages of both a landing and rejected takeoff. Thrust reversers are used by many turbofan engine aircraft to slow down just after touch-down, reducing brake wear and enabling shorter landing distances. Reverse thrust is typically applied immediately after touchdown to improve deceleration early in the landing [1].
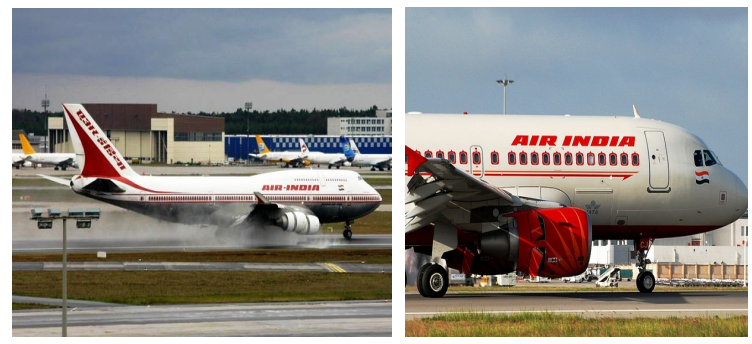

Fig. 1 Thrust reversers deployed on turbofan of an Air India Boeing 747-400 landing at Indira Gandhi International Airport, New Delhi (left), Air India Airbus A319 with thrust reversers deployed on turbofan engine for pushback i.e."Power Back" (right). [5]
One common misconception about thrust reversing is that the engine itself actually runs in reverse, but this is not the case. In other words, air does not come in through the nozzle of the engine and exhausted through the inlet to "reverse" the thrust. The engine itself still operates in the same manner, but the thrust it generates is redirected to reverse direction to produce drag.
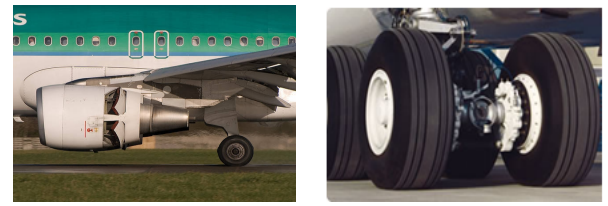

Fig. 2 Different decelerating devices installed on current commercial aircrafts including thrust reversers in turbofan engine (left) and wheel brakes in landing gears (right).

\section{A. Necessity of thrust reverser mechanism}

Thrust reverser mechanism are required by an aircraft to reverse maximum amount of thrust available, to reduce brake wear, to reduce taxi distance, to reduce certified landing field lengths, to provide additional stopping force on wet, slushy and icy runways, for refused takeoffs, to reverse maximum thrust for power back and in addition to wheel brakes, the engine can also be used to stop an aircraft.

\section{AIRCRAFT RUNWAY PERFORMANCE}

Application of thrust reverser mechanism results in reduction of landing run which directly effects aircraft runway performance in positive manner.

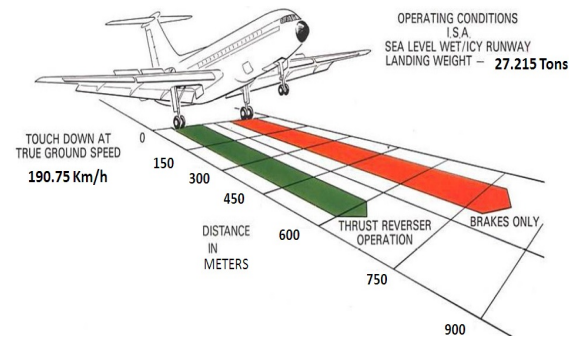

Fig. 3 Comparative landing runs with and without thrust reversal and it is seen that by using thrust reversers, landing is reduced up to an extent and this effect is more in slippery and icy runways. [1] 


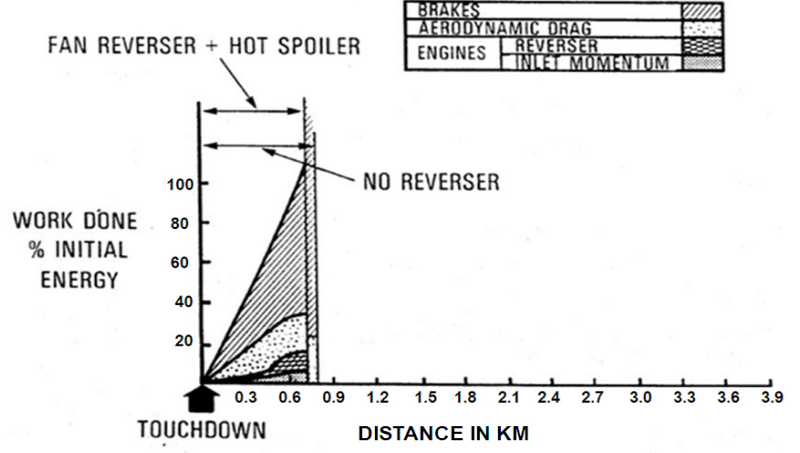

Fig. 4 Graph shows relation b/w Work done and Landing run with respect to use of Thrust reversers in Dry Runways. [2]

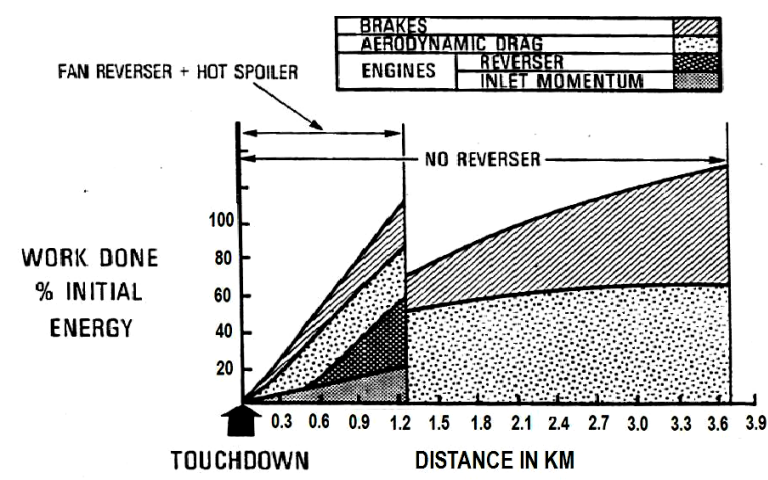

Fig. 5 Graph shows relation $\mathrm{b} / \mathrm{w}$ work done and landing run with respect to use of thrust reversers in icy/wet runways, and it is seen that landing run is reduced about $2.5 \mathrm{Kms}$. [2]

The airlines accept that thrust reversers are necessary for safe operations. In general, the airlines feel that thrust reversers provide an added margin of safety for transport aircraft operations. [2]

\section{TYPES OF THRUST REVERSER MECHANISM INSTALLED IN A TURBOFAN ENGINE}

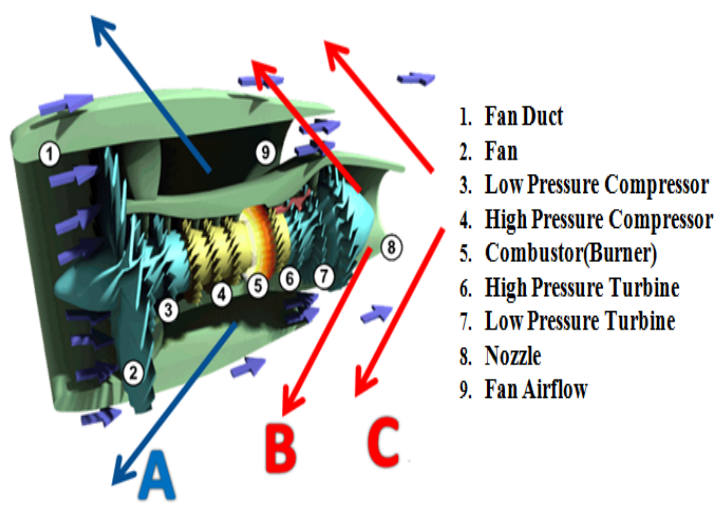

Fig. 6 Animated cross-section of turbofan engine showing different parts and arrows show ways of reversing thrust.[7]
Thrust of turbofan engine can be reverser in three different ways [1]

\section{A. Cascade type reverser system (cold stream)}

The cold stream reverser system can be actuated by an air motor, the output of which is converted to mechanical movement by a series of flexible drives, gearboxes and screwjacks, or by a system using hydraulic rams. When the engine is operating in forward thrust, the cold stream final nozzle is 'open' because the cascade vanes are internally covered by the blocker doors (flaps) and externally by the movable (translating) cowl; the latter item also serves to reduce drag. On selection of reverse thrust, the actuation system moves the translating cowl rearwards and at the same time folds the blocker doors to blank off the cold stream final nozzle, thus diverting the airflow through the cascade vanes.
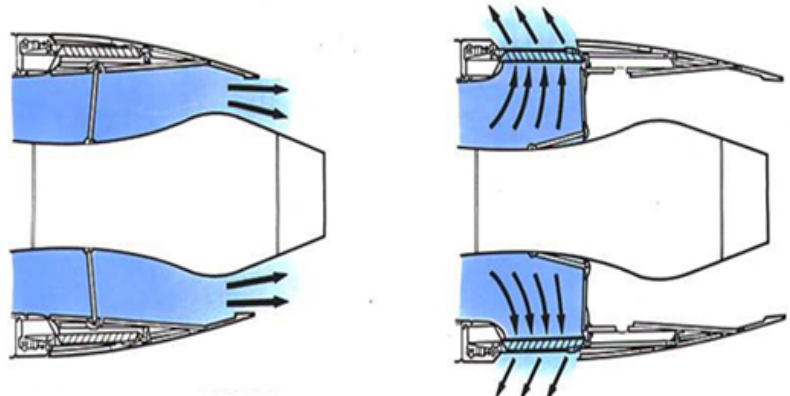

Fig. 7 Cascade type thrust reverser system using cold fan stream for reverser of thrust of a turbofan engine.

\section{B. Clamshell door system (hot stream)}

The clamshell door system is a pneumatically operated system. On the selection of reverse thrust, the doors rotate to uncover the ducts and close the normal gas stream exit. Cascade vanes then direct the gas stream in a forward direction so that the jet thrust opposes the aircraft motion. The clamshell doors are operated by pneumatic rams through levers that give the maximum load to the doors in the forward thrust position; this ensures effective sealing at the door edges, so preventing gas leakage. The door bearing and operating linkage operate without lubrication at temperatures of up to $600^{\circ} \mathrm{C}$.
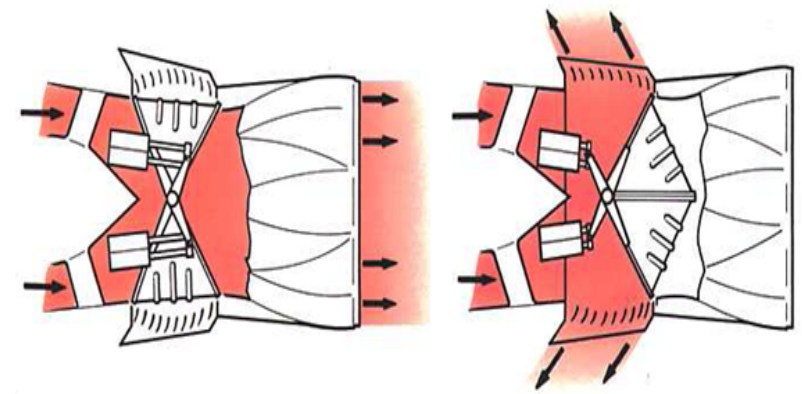

Fig. 8 Thrust reverser system using clamshell doors which are installed after turbine but before nozzle of a turbofan engine. 


\section{Bucket target system (hot stream)}

The bucket target system is hydraulically actuated and uses bucket-type doors to reverse the hot gas stream. The thrust reverser doors are actuated by means of a conventional pushrod system. A single hydraulic powered actuator is connected to a drive idler, actuating the doors through a pair of pushrods (one for each door). The reverser doors are kept in synchronization through the drive idler. The hydraulic actuator incorporates a mechanical lock in the stowed position. In the forward thrust mode the thrust reverser doors form the convergent-divergent final nozzle for the engine.

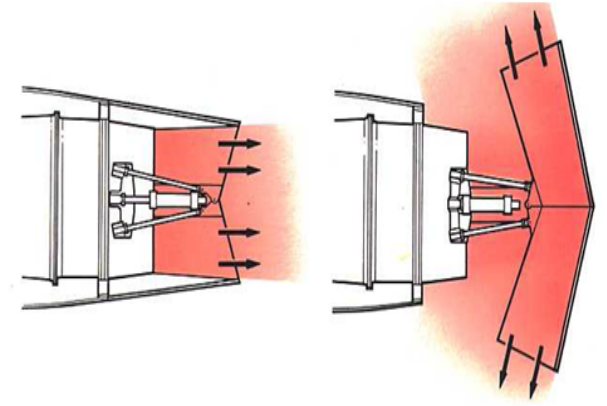

Fig. 9 Bucket target type thrust reverser system using deflector doors which are installed after nozzle of a turbofan engine.

\section{TECHNICAL ASPECTS REGARDING THRUST REVERSER MECHANISM}

\section{A. Engine power reverse thrust characteristics}

Engine power reverse thrust characteristics can be drawn as per the rated $\mathrm{rpm}$ and $\%$ of rated thrust, it is observed that Reverse thrust is max. at higher speeds of Engine. So, Thrust reversers are more efficient at higher engine rpm.

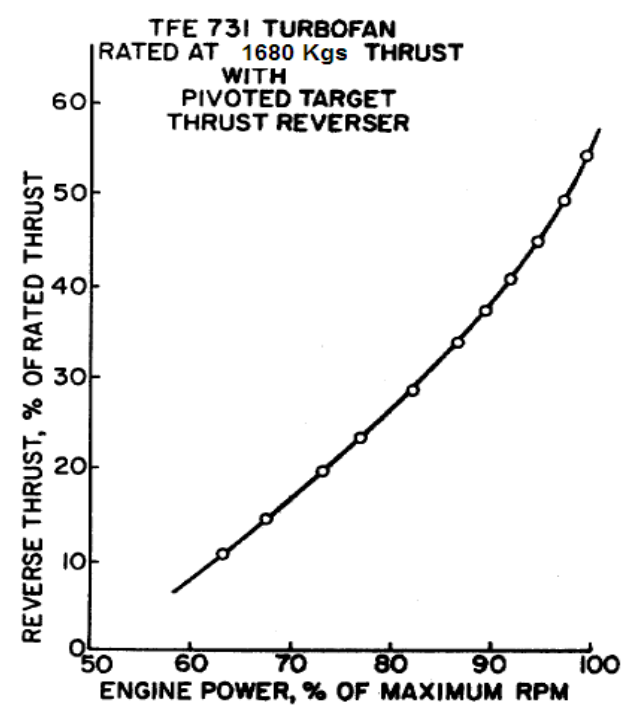

Fig. 10 Graph for a turbofan engine of reverse thrust data versus engine power level for the reverser geometry of an embodiment of the bucket target type thrust reverser in the deployed position. [4]

\section{B. Modes of operation of thrust reverser mechanism}

Thrust reverser is used in three positions after landing of an aircraft which are as follows:

1. Forward thrust (no reverse)

2. Idle thrust reverse (partial reverse)

3. Normal thrust reverser (full reverse)
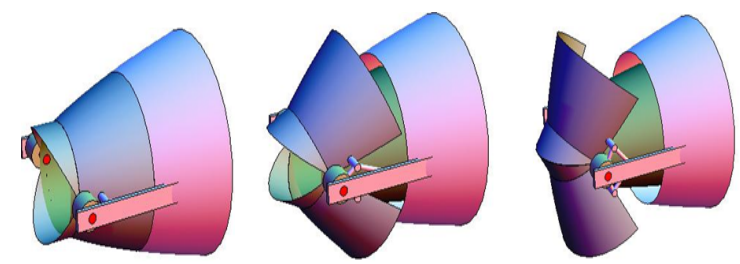

Fig. 11 Different modes of deployment of thrust reverser mechanism at forward, idle, normal positions (from left to right). [6]

\section{Speed limits for different modes of thrust reverser}

Reverse thrust is most effective when used at high runway speeds i.e. $190 \mathrm{Km} / \mathrm{h}$ to $130 \mathrm{Km} / \mathrm{h}$ and less effective at low speeds; therefore early selection of Normal reverse thrust is desirable. Use of reverse thrust at speeds below approximately $130 \mathrm{Km} / \mathrm{h}$ to $110 \mathrm{Km} / \mathrm{h}$ can cause engine damage through sand, stones and other foreign objects entering the intake having been initially lifted off the runway by the forward flowing air. Engine surging is also a possibility as the hot exhaust air is re-ingested at the intake. So, Idle Reverse mode should be used from $120 \mathrm{Km} / \mathrm{h}$ to reduced speed of $40 \mathrm{~km} / \mathrm{h}$.

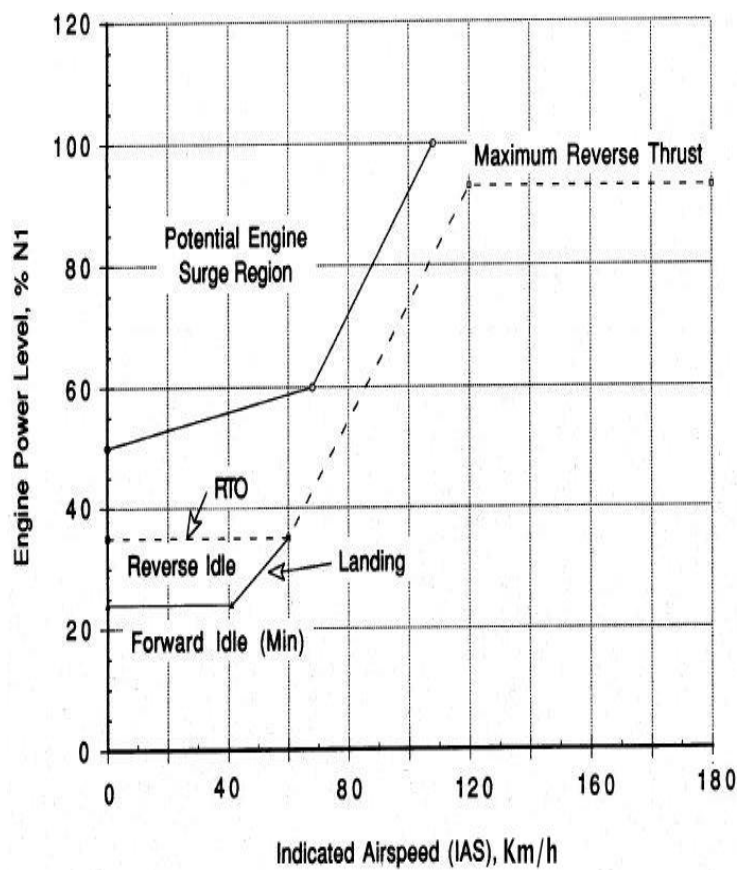

Fig. 12 Graph shows a relation b/w engine power levels and indicated airspeed from the speed limitation for thrust reverser deployment in normal, idle, forward modes. [2] 


\section{Technical problems}

Typical problems encountered with thrust reversers are sensor or indicator problems, inability to stow or deploy due to mechanical problems, wear, leaks and acoustic treatment delaminations. [3]

\section{THRUST REVERSER \& ENGINE MAINTENANCE SCHEDULE}

The use of thrust reversers has negligible impact on airline maintenance schedules. Thrust reverser maintenance activities are performed along with routine engine and airframe inspections. The schedules used for thrust reversers such as cascade reversers for high bypass engines coincide with airframe inspections. The schedules used for engine mounted thrust reversers such as bucket target type coincide with engine inspections. Therefore, thrust reversers do not directly affect airframe or power-plant i.e. turbofan engine maintenance schedules. Engine maintenance schedules are typically based on a combination of engine hours and cycles. Engine cycles per flight are factored into the flight hour referenced maintenance schedules for each aircraft type. It should also be noted that an engine cycle is defined as a flight cycle where a takeoff and landing or rejected takeoff was made. The deployment of the thrust reverser and a change in engine power setting during landing is not considered as an additional engine cycle. An engine run-up for maintenance checkout would also not be counted as an engine cycle. This definition is used throughout the airline industry. [2]

\section{CONCLUSION}

In the present scenario with the implementation of this technique of additional deceleration system several accidents can be avoided in wet runways and in adverse climatic conditions. This technique shows how the energy that would go in vain would be utilized in a positive manner. In practice, the application of thrust reverser types depends on the engine used. This mechanism is employed for improving aircraft runway performance and it is observed that by using thrust reverser especially in wet runway there is considerable reduction in landing run which is responsible for safety of passenger aircraft. Maximum level of reversal can be achieved by using the system in specified range of speeds. Typical problems encountered with thrust reversers can be eliminated by regular inspection of the mechanism. It has been observed several times that use of thrust reverser mechanism prevents accident during ground operation mainly in slippery runways. This emphasizes the needs and benefits for a powered thrust reverser system for optimum safety and operability. For this reason proper schedule for maintenance of thrust reverser mechanism is designed along with turbofan engine maintenance schedule which is profit oriented from both time and cost point of view. Any successful landing made using thrust reversers during adverse weather conditions and wet runways demonstrates the benefits of thrust reverser.

\section{REFERENCES}

[1] Rolls-Royce, The Jet Engine, 5th ed., Derby, England: The Technical Publications Department, Rolls-Royce plc, 1996.

[2] Jeffrey A. Yetter, "Why Do Airlines Want and Use Thrust Reversers," A Compilation of Airline Industry Responses to a Survey Regarding the Use of Thrust Reversers on Commercial Transport Airplanes, Tech. Rep.TM-109158, Langley Research Center, Hampton, Virginia, January 1995.

[3] Thrust Reversing Systems, Power plant Installation HWG, Transport Airplane and Engine, Federal Aviation Administration, ARMC, FAR Std. 25.933, 1992.

[4] William K. Great house, New York, "Thrust Reverser Nozzle," U.S. Patent 4147 027, April 1979.

[5] The Wikipedia website. Available: http://en.wikipedia.org/wiki/Air_India

[6] The Wolfram website. Available: http://demonstrations.wolfram.com/ThrustReverser/

[7] Turbofan Labelled.gif. Available: http://en.wikipedia.org/wiki/File:Turbofan_Labelled.gif

\section{Creative Commons Attribution License 4.0 (Attribution 4.0 International, CC BY 4.0)}

This article is published under the terms of the Creative Commons Attribution License 4.0 https://creativecommons.org/licenses/by/4.0/deed.en_US 